\title{
Short communication: Genetic parameter estimates for caprine arthritis encephalitis in dairy goats
}

\author{
E. B. Schultz, ${ }^{1 *}$ T. E. Z. Santana, ${ }^{1 *}$ F. F. Silva, ${ }^{1}$ A. O. Garcia, ${ }^{1}$ H. R. Oliveira, ${ }^{2,3}$ M. T. Rodrigues, ${ }^{1}$ and L. F. Brito ${ }^{2} \dagger$ \\ ${ }^{1}$ Departament of Animal Science, Federal University of Viçosa, Viçosa, Minas Gerais, 36570-900, Brazil \\ ${ }^{2}$ Department of Animal Sciences, Purdue University, West Lafayette, IN 47907 \\ ${ }^{3}$ Department of Animal Biosciences, University of Guelph, Guelph, Ontario, N1G 2W1, Canada
}

\section{ABSTRACT}

Caprine arthritis encephalitis (CAE) is a chronic disease caused by a retrovirus from the Lentivirus genus. No effective vaccines or treatments exist, and therefore genetic selection for CAE resistance might be a feasible alternative. To our best knowledge, no other studies have investigated the genetic architecture of $\mathrm{CAE}$ resistance in dairy goats. In this context, this study was designed to estimate genetic parameters for CAE infection in Alpine and Saanen goats using a Bayesian threshold model. A total of 542 adult goats (and $>3$-generation pedigree), which were group-housed in a population with high CAE prevalence, were tested based on a serological infection assessment test (negative $=1$ or positive $=2$ ) and used for this study. Genetic parameters were estimated using the BLUPF90 family programs. There was considerable genetic variability for CAE resistance, and pedigree-based heritability was significantly different from zero $(0.026<$ heritability $<0.128)$. Our findings indicate that the prevalence of CAE in goat herds can be reduced or eliminated through direct genetic selection for $\mathrm{CAE}$ resistance in addition to proper management strategies.

Key words: caprine arthritis encephalitis, disease resistance, heritability, Lentivirus genus, virus infection

\section{Short Communication}

The caprine arthritis encephalitis virus (CAEV) from the genus Lentivirus, first isolated in 1980 (Crawford et al., 1980), is the agent of the chronic disease defined as caprine arthritis encephalitis (CAE). This disease is a problem around the world, with high CAEV prevalence reported in various goat populations, including 98.5, $80.4,51.6,23.2,28.6,10.3,82.0,73.0,18,35.3,35.4$

Received October 12, 2019.

Accepted February 20, 2020.

*These authors contributed equally to this work.

†Corresponding author: britol@purdue.edu to 81.1 , and $21.9 \%$ of herds (or animals) infected in Taiwan, Canada, Lebanon, Jordan, Mexico, the United Kingdom, Australia, the United States, Spain, Egypt, Poland, and Croatia, respectively (Dawson and Wilesmith, 1985; Grewal et al., 1986; Cutlip et al., 1992; Al-Qudah et al., 2006; Vallerand et al., 2007; Ghanem, 2011; Oem et al., 2012; Martínez-Navalón et al., 2013; Stonos et al., 2013; Jones, 2014; Tabet et al., 2015; Tariba et al., 2015; Waseem et al., 2015; Thomann et al., 2017; Yang et al., 2017; Gruszecki et al., 2018). This disease causes major economical and welfare problems for the worldwide goat industry, including reduced production, growth rate, and longevity; greater rate of reproductive failures; premature culling; and increased incidence of disease (Smith and Cutlip, 1988; Peterhans et al., 2004; Reina et al., 2009; Leitner et al., 2010; Murphy et al., 2010; Konishi et al., 2011; Kaba et al., 2012; Tageldin et al., 2012; Martínez-Navalón et al., 2013). Additionally, CAE is a limiting factor for trade of animals across local herds and internationally, as this disease is controlled by biosecurity barriers (Bezerra Júnior et al., 2018). The main symptoms of CAEV infection are swelling and inflammation of carpal joints and other organ or tissues (bursae, brain, spinal cord, lungs); muscle tremors; depressive behavior; repeated walking in circles; hitting the head against the wall repeatedly during the day; exaggerated head twitch and head tilt (Figure 1); clinical mastitis; lymphadenopathy; interstitial pneumonia; and encephalitis (McGuire et al., 1990; Reina et al., 2009; Leitner et al., 2010; Leroux et al., 2010; Blacklaws, 2012).

Caprine arthritis encephalitis is mainly transmitted from does to their offspring through ingestion of infected colostrum or milk or through direct contact with other body secretions, which might contain free viral particles and infected macrophages or epithelial cells (Péretz et al., 1994; Blacklaws et al., 2004; Linderot de Cardona et al., 2016). The disease is usually controlled by identifying and culling CAEV-positive individuals and removing kids at birth from the doe and feeding temperature-treated colostrum or milk to prevent con- 

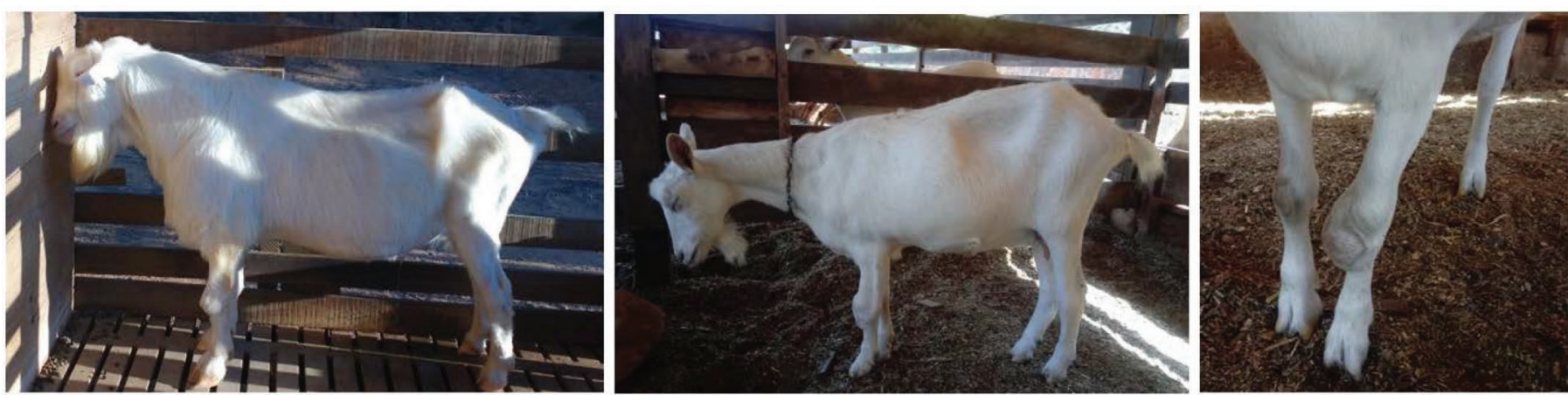

Figure 1. Appearance of a goat infected with caprine arthritis encephalitis virus (advanced stage) in which the animal is hitting its head against the pen wall (left picture), is displaying depressive behavior (middle picture), and has joint inflammation (right picture).

tact and transmission. Other intervention strategies that have been investigated include the development of vaccines and drug treatments. However, their effectiveness is low and likely not cost effective because CAEV is very adaptable and evolves rapidly (Reina et al., 2009; Barquero et al., 2013; White and Knowles, 2013). Drug treatments exist for some lentiviral agents, such as highly active anti-retroviral treatment for use against HIV (Olender et al., 2012), and could theoretically be used for CAEV. However, this would not be cost effective (White and Knowles, 2013).

The most accurate CAE diagnosis is done using the ELISA and agar gel immunodiffusion methods (Bezerra Júnior et al., 2018), which are expensive, especially for smallholders. However, considering the reduction in production and longevity, as mentioned above, these tests might be cost effective depending on CAEV prevalence and herd size. In addition, CAEV is difficult to eradicate because goats can be seronegative and continue shedding in milk for months postinfection. Thus, we can conclude that CAEV eradication has been a major challenge for the worldwide goat industry (Martínez-Navalón et al., 2013). In this context, some countries and producers have opted for not pursuing testing and eradication programs (White and Knowles, 2013), which results in long-term welfare and economic implications for the goat industry.

There is evidence of breed differences in seroprevalence of CAEV and thus a genetic basis for probability of infection (Grewal et al., 1986; Vitu and Russo, 1988; Rowe et al., 1992; White and Knowles, 2013). However, to our best knowledge, no studies have investigated within-population genetic variability. Genetic selection for CAE-resistant goats could play a major role in improving welfare and increasing industry profitability by reducing CAE prevalence in herds. Even though disease susceptibility has been mainly affected by environmental factors, genetic variation can also contribute to the level of infection resistance (Brito et al., 2018;
Colussi et al., 2019). In this context, the main objective of this study was to estimate variance components and genetic parameters for CAE resistance using Bayesian threshold models, which consider the binary nature of the trait. The main dairy goat breeds raised around the world are Alpine, Saanen, and crosses involving these 2 breeds. Alpine and Saanen goats originated in the French and Swiss Alps and have been exported all over the world in the past few decades. Therefore, it is reasonable to hypothesize that the genetic background of CAE resistance in these 2 populations from different countries is similar.

A total of 542 adult goats, which were group-housed in a population with high CAE prevalence $(30.12 \%)$, were serologically tested for CAEV infection (negative $=1$ and positive $=2$ ). Serological infection assessment was carried out between 2014 and 2018 in Alpine and Saanen animals from an experimental goat research herd from the Federal University of Viçosa (Viçosa, Minas Gerais, Brazil). This herd was established by importing animals (or using AI) from all over the country and internationally (e.g., France). Contemporary groups (CG) were defined based on breed group (Alpine or Saanen), sex, and birth date (month and year). Sex was included in the CG because males and females are kept in separate facilities. Only CG with more than 3 animals were kept for further analyses. After data editing, CAEV serological tests from 447 goats (292 Alpine and 155 Saanen; 435 females and 12 males) were available for the analyses. The age at the testing date was also included as a linear covariate in the statistical model. The age at testing ranged from 365 to $1,460 \mathrm{~d}$ (1 to $4 \mathrm{yr}$; average $\pm \mathrm{SD}=1,001 \pm 618 \mathrm{~d}$ ). Genealogical information provided a pedigree-based relationship matrix spanning at least 3 generations. The average inbreeding coefficient was $0.011 \pm 0.046$.

Blood serological tests for CAEV infection were carried out using samples collected from the jugular vein puncture with evacuated tubes without anticoagulant. 
After collection, the blood samples were immediately centrifuged at $1,610 \times g$ for $5 \mathrm{~min}$ at room temperature. The plasma samples were pipetted and refrigerated at $-20^{\circ} \mathrm{C}$ for further analysis. The plasma was submitted to the agar gel immunodiffusion test using commercial Biovetech kits (Biovetech, Recife, PE, Brazil) that detect the presence or absence of specific CAEV antibodies. Infection with CAEV was considered to be a categorical binary trait and was recoded as 1 (negative) or 2 (positive). Although this is a categorical phenotype, it is assumed to be similarly inherited as continuous traits by using threshold models (Berghof et al., 2019). Under this approach, a continuous latent variable, often named liability (Falconer and Mackay, 1996), is associated with the observed categorical response. Given the statistical complexity behind this process, Bayesian inference is strongly recommended (Sorensen and Gianola, 2002). This model can be represented as

$$
\mathbf{l}=\mathbf{X} \boldsymbol{\beta}+\mathbf{Z} \mathbf{u}+\mathbf{e},
$$

where $\mathbf{l}$ is the unobservable underlying liabilities vector for the categorical CAE trait (negative $=1$ and positive $=2$ ); $\boldsymbol{\beta}$ is the vector of systematic effects (age at the testing date and $\mathrm{CG}$ ); $\mathbf{u}$ is the vector of additive genetic effects (i.e., EBV); e is the vector of random residuals; and $\mathbf{X}$ and $\mathbf{Z}$ are incidence matrices related to $\boldsymbol{\beta}$ and $\mathbf{u}$, respectively. The data distribution for CAE was assumed to be

$$
\begin{aligned}
& f\left(\mathbf{y} \mid \mathbf{l}, \mathbf{b}, \mathbf{u}, \sigma_{a}^{2}, \sigma_{e}^{2}, \tau\right)=\prod_{i=1}^{n} f\left(y_{i} \mid l_{i}\right)= \\
& \prod_{i=1}^{n} \mathbf{I}\left(\mathbf{l}_{i}<\tau\right) \mathbf{I}\left(y_{i}=1\right)+\left(\mathbf{l}_{i}>\tau\right) \mathbf{I}\left(y_{i}=2\right),
\end{aligned}
$$

where $\mathbf{y}$ is the vector of observed values, $\tau$ is the threshold value that defines the 2 response categories ( 1 and 2 ), and $\sigma_{\mathrm{a}}^{2}$ and $\sigma_{e}^{2}$ are the additive genetic and residual variances, respectively. Because y conditionally depends on the liability distribution, (l), $\mathbf{l}$ is given as

$$
\mathbf{l} \mid \boldsymbol{\beta}, \mathbf{u}, \sigma_{u}^{2}, \sigma_{e}^{2}, \tau \sim N\left(\mathbf{X} \boldsymbol{\beta}+\mathbf{Z u}, \mathbf{I} \sigma_{e}^{2}\right),
$$

where all terms were previously described and I (the letter shown within parentheses) is an identity matrix. The prior distributions for the other parameters of the model are as follows: $\boldsymbol{\beta}$ and $\tau$ assume uniform distributions (representing noninformative prior), $\mathbf{u} \sim N\left(0, \mathbf{A} \sigma_{u}^{2}\right)$, $\sigma_{u}^{2} \sim \chi^{-2}\left(v_{u}, s_{u}^{2}\right)$, and $\sigma_{e}^{2} \sim \chi^{-2}\left(v_{e}, s_{e}^{2}\right)$. Here, $N$ and $\chi^{-2}$ indicate normal and scaled inverse chi-squared distributions, respectively; $\mathbf{A}$ is the pedigree-based relationship matrix; and $v_{u}, s_{u}^{2}, v_{e}$, and $s_{e}^{2}$ are the hyperparameters of prior distributions for the additive genetic $\left(\sigma_{u}^{2}\right)$ and residual $\left(\sigma_{e}^{2}\right)$ variance components, respectively.

A total of 500,000 Markov chain Monte Carlo iterations were considered to fit the mentioned threshold Bayesian model via THRGIBBS1F90 software (Tsuruta and Misztal, 2006) using the Gibbs sampler algorithm. The burn-in and thin periods were considered as 100,000 and 10 iterations, respectively. The convergence of the Gibbs sampler algorithm was validated by the Geweke test, implemented in the "boa" package in R (Smith, 2007). The posterior marginal distribution samples for heritability were given as $h^{2(k)}=\frac{\sigma_{u}^{2(k)}}{\left(\sigma_{u}^{2(k)}+\sigma_{e}^{2(k)}\right)}$, with $k$ being each Markov chain Monte Carlo iteration. Mean, standard deviation, and 95\% highest posterior density intervals were calculated for the heritability using the posterior distribution.

Variance components and heritability estimates are shown in Table 1. In brief, heritability estimated for CAE resistance was significantly different from zero $(0.026<$ heritability $<0.128)$, indicating that direct genetic selection for CAE resistance will result in reduction or elimination of CAEV in goat herds. To our best knowledge, this is the first report of variance components and genetic parameters for CAE. Therefore, estimates reported here can be used in genetic evaluations performed in other goat herds to predict accurate breeding values for CAE resistance. As CAE is one of the main sources of economic loss and welfare issues in goat farms worldwide, breeding values for CAE resistance can be incorporated into goat breeding programs. Together with management strategies, including CAE resistance in the goat industry breeding goals will enable eliminating this virus from goat herds and therefore reduce the costs from serological tests, eliminate welfare issues, and minimize production losses. Usually, health traits are lowly heritable (e.g., Silva et al., 2018; Snyman and Fisher, 2019), but genetic progress has been shown through selective breeding (Miglior et al., 2017). It is worth highlighting that genetic selection does not have to be the sole intervention approach but rather can complement existing management and nutrition strategies. Increased understanding of host genetics will play an important role in understanding CAEV-host interactions, which will be advanced in future studies incorporating genomic information. 
Table 1. Posterior means and SD with the respective $95 \%$ highest posterior density intervals (HPD95\%) for additive genetic and residual variances and heritability (liability scale) estimates for resistance to the caprine arthritis encephalitis virus

\begin{tabular}{lcccc}
\hline & & & \multicolumn{2}{c}{ HPD95\% } \\
\cline { 4 - 5 } Parameter & Mean & SD & Lower & Upper \\
\hline Additive genetic variance & 0.096 & 0.011 & 0.063 & 0.129 \\
Residual variance & 1.039 & 0.008 & 1.015 & 1.063 \\
Heritability & 0.077 & 0.017 & 0.026 & 0.128 \\
\hline
\end{tabular}

Similarly to many other novel traits, CAEV phenotyping is still costly for producers, and thus no large data sets in pedigreed populations are available for research purposes. The sample size used for this study is a limiting factor. However, considering the data set structure and the genetic representation of the national population, the results observed here are likely to be representative of the national Alpine and Saanen population. As more individuals are phenotyped, this study should be repeated as well as validated in other international populations. Furthermore, it is worth noting that the greater adoption of genomic selection in the dairy goat industry (Rupp et al., 2016) will enable genetic improvement for CAE resistance in herds with no routine CAEV testing as long as there are genetic links with animals from herds under testing. To our best knowledge, this is the first study reporting genetic parameters for CAEV infection resistance, and the results observed are expected to instigate other researchers to perform similar analyses in other populations and technology companies to develop cheaper tests for genetic selection purposes.

\section{ACKNOWLEDGMENTS}

The authors acknowledge financial support from the Brazilian National Council for Scientific and Technological Development (CNPq, Brasilia, DF, Brazil). The authors have not stated any conflicts of interest.

\section{REFERENCES}

Al-Qudah, K., A. M. Al-Majali, and Z. B. Ismail. 2006. Epidemiological studies on caprine arthritis-encephalitis virus infection in Jordan. Small Rumin. Res. 66:181-186. https://doi.org/10.1016/j .smallrumres.2005.09.020.

Barquero, N., E. Gomez-Lucia, A. Arjona, C. Toural, A. Heras, J. Fernández-Garayzabal, and A. Domenech. 2013. Evolution of specific antibodies and proviral DNA in milk of small ruminants infected by small ruminant lentivirus. Viruses 5:2614-2623. https:// doi.org/10.3390/v5102614.

Berghof, T. V. L., M. Poppe, and H. A. Mulder. 2019. Opportunities to improve resilience in animal breeding programs. Front. Genet. 9:692-707. https://doi.org/10.3389/fgene.2018.00692.

Bezerra Júnior, R. Q., Â. M. X. Eloy, J. R. Furtado, R. R. Pinheiro, A. Andrioli, F. B. Moreno, M. D. Pinto Lobo, A. C. O. Monteiro-
Moreira, R. de Azevedo Moreira, T. M. Farias Pinto, and M. F. da Silva Teixeira. 2018. A panel of protein candidates for comprehensive study of Caprine Arthritis Encephalitis (CAE) infection. Trop. Anim. Health Prod. 50:43-48. https://doi.org/10.1007/ s11250-017-1398-1.

Blacklaws, B. A. 2012. Small ruminant lentiviruses: Immunopathogenesis of visna-maedi and caprine arthritis and encephalitis virus. Comp. Immunol. Microbiol. Infect. Dis. 35:259-269. https://doi .org/10.1016/j.cimid.2011.12.003.

Blacklaws, B. A., E. Berriatua, S. Torsteinsdottir, N. J. Watt, D. de Andres, D. Klein, and G. D. Harkiss. 2004. Transmission of small ruminant lentiviruses. Vet. Microbiol. 101:199-208. https://doi .org/10.1016/j.vetmic.2004.04.006.

Brito, L. F., S. Mallikarjunappa, M. Sargolzaei, A. Koeck, J. Chesnais, F. S. Schenkel, K. G. Meade, F. Miglior, and N. Karrow. 2018. The genetic architecture of milk ELISA scores as an indicator of Johne's disease (paratuberculosis) in dairy cattle. J. Dairy Sci. 101:10062-10075. https://doi.org/10.3168/jds.2017-14250.

Colussi, S., R. Desiato, C. Beltramo, S. Peletto, P. Modesto, M. G. Maniaci, V. Campia, A. Quasso, S. Rosati, S. Bertolotti, G. Ru, and P. L. Acutis. 2019. A single nucleotide variant in the promoter region of the $C C R 5$ gene increases susceptibility to arthritis encephalitis virus in goats. BMC Vet. Res. 15:230-236. https://doi .org/10.1186/s12917-019-1979-5.

Crawford, T. B., D. S. Adams, W. P. Cheevers, and L. C. Cork. 1980. Chronic arthritis in goats caused by a retrovirus. Science 207:997999. https://doi.org/10.1126/science.6153243.

Cutlip, R. C., H. D. Lehmkuhl, J. M. Sacks, and A. L. Weaver. 1992. Prevalence of antibody to caprine arthritis-encephalitis virus in goats in the United States. J. Am. Vet. Med. Assoc. 200:802-805.

Dawson, M., and J. W. Wilesmith. 1985. Serological survey of lentivirus (maedi-visna/caprine arthritis-encephalitis) infection in British goat herds. Vet. Rec. 117:86-89. https://doi.org/10.1136/vr .117.4.86.

Falconer, D. S., and T. F. C. Mackay. 1996. Introduction to Quantitative Genetics. Longman, Essex, UK.

Ghanem, Y. M. A. R. 2011. A serological investigation of caprine arthritis encephalitis virus (CAEV) in goats by competitive ELISA at Kafrelsheikh Governorate, Egypt. Assiut Vet. Med. J. 57:184196.

Grewal, A. S., R. W. Burton, J. E. Smith, E. M. Batty, P. E. Greenwood, and R. North. 1986. Caprine retrovirus infection in New South Wales: Virus isolations, clinical and histopathological findings and prevalence of antibody. Aust. Vet. J. 63:245-248. https:/ /doi.org/10.1111/j.1751-0813.1986.tb02985.x.

Gruszecki, T. M., M. Olech, J. Kuźmak, E. Bagnicka, A. Szymanowska, K. Szczepaniak, M. Greguła-Kania, K. Tomczuk, and W. Bojar. 2018. Prevalence of CAEV infections in goat herds. Med. Welt 74:536-539. https://doi.org/10.21521/mw.6100.

Jones, D. V. M. 2014. The current prevalence of caprine arthritisencephalitis virus in Midwestern goat herds. MS Thesis. University of Nebraska, Lincoln.

Kaba, J., N. Strzalkowska, A. Jozwik, J. Krzyzewski, and E. Bagnicka. 2012. Twelve-year cohort study on the influence of caprine arthritis-encephalitis virus infection on milk yield and composition. J. Dairy Sci. 95:1617-1622. https://doi.org/10.3168/jds.2011-4680.

Konishi, M., Y. Nagura, N. Takei, M. Fujita, K. Hayashi, M. Tsukioka, T. Yamamoto, K. Kameyama, H. Sentsui, and K. Murakami. 2011. Combined eradication strategy for CAE in dairy goat farm in Japan. Small Rumin. Res. 99:65-71. https://doi.org/10.1016/j .smallrumres.2011.03.051.

Leitner, G., O. Krifucks, L. Weisblit, Y. Lavi, S. Bernstein, and U. Merin. 2010. The effect of caprine arthritis encephalitis virus infection on production in goats. Vet. J. 183:328-331. https://doi.org/ 10.1016/j.tvjl.2008.12.001.

Leroux, C., J. C. Cruz, and J. F. Mornex. 2010. SRLVs: A genetic continuum of lentiviral species in sheep and goats with cumulative evidence of cross species transmission. Curr. HIV Res. 8:94-100. https://doi.org/10.2174/157016210790416415.

Linderot de Cardona, K., A. De Gracia Scanapieco, and P. G. Braun. 2016. First results on small ruminant brucellosis and tuberculo- 
sis and caprine arthritis-encephalitis in El Salvador. Trop. Anim. Health Prod. 48:1083-1087. https://doi.org/10.1007/s11250-016 $-1044-3$.

Martínez-Navalón, B., C. Peris, E. A. Gómez, B. Peris, M. L. Roche, C. Caballero, E. Goyena, and E. Berriatua. 2013. Quantitative estimation of the impact of caprine arthritis encephalitis virus infection on milk production by dairy goats. Vet. J. 197:311-317. https: //doi.org/10.1016/j.tvjl.2012.12.020.

McGuire, T. C., K. I. O'Rourke, D. P. Knowles, and W. P. Cheevers. 1990. Caprine arthritis encephalitis lentivirus transmission and disease. Curr. Top. Microbiol. Immunol. 160:61-75. https://doi .org/10.1007/978-3-642-75267-4_4.

Miglior, F., A. Fleming, F. Malchiodi, L. F. Brito, P. Martin, and C. F. Baes. 2017. A 100-year review: Identification and genetic selection of economically important traits in dairy cattle. J. Dairy Sci. 100:10251-10271. https://doi.org/10.3168/jds.2017-12968.

Murphy, B., V. McElliott, N. Vapniarsky, A. Oliver, and J. Rowe. 2010. Tissue tropism and promoter sequence variation in caprine arthritis encephalitis virus infected goats. Virus Res. 151:177-184. https://doi.org/10.1016/j.virusres.2010.05.002.

Oem, J. K., J. Y. Chung, J. W. Byun, H. Y. Kim, D. Kwak, and B. Y. Jung. 2012. Large-scale serological survey of caprine arthritisencephalitis virus (CAEV) in Korean black goats (Capra hircus aegagrus). J. Vet. Med. Sci. 74:1657-1659.

Olender, S., T. J. Wilkin, B. S. Taylor, and S. M. Hammer. 2012. Advances in antiretroviral therapy. Top. Antivir. Med. 20:61.

Péretz, G., F. Bugnard, and D. Calavas. 1994. Study of a prevention programme for caprine arthritis- encephalitis. Vet. Res. 25:322326.

Peterhans, E., T. Greenland, J. Badiola, G. Harkiss, G. Bertoni, B. Amorena, M. Eliaszewicz, R. Juste, R. Krassnig, J. Lafont, P. Lenihan, G. Pétursson, G. Pritchard, J. Thorley, C. Vitu, J. Mornex, and M. Pépin. 2004. Routes of transmission and consequences of small ruminant lentiviruses (SRLVs) infection and eradication schemes. Vet. Res. 35:257-274. https://doi.org/10 .1051/vetres:2004014.

Reina, R., E. Berriatua, L. Lujan, R. Juste, A. Sanchez, D. de Andres, and B. Amorena. 2009. Prevention strategies against small ruminant lentiviruses: An update. Vet. J. 182:31-37. https://doi.org/ 10.1016/j.tvjl.2008.05.008.

Rowe, J. D., N. E. East, C. E. Franti, M. C. Thurmond, N. C. Pedersen, and G. H. Theilen. 1992. Risk factors associated with the incidence of seroconversion to caprine arthritis-encephalitis virus in goats on California dairies. Am. J. Vet. Res. 53:2396-2403.

Rupp, R., S. Mucha, H. Larroque, J. McEwan, and J. E. Conington. 2016. Genomic application in sheep and goat breeding. Anim. Front. 6:39-44. https://doi.org/10.2527/af.2016-0006.

Silva, F. F., J. C. Bambou, J. A. Oliveira, C. Barbier, J. Fleury, T. Machado, and N. Mandonnet. 2018. Genome wide association study reveals new candidate genes for resistance to nematodes in Creole goat. Small Rumin. Res. 166:109-114. https://doi.org/10 .1016/j.smallrumres.2018.06.004.

Smith, B. J. 2007. Boa: An R Package for MCMC output convergence. J. Stat. Softw. 21:1-37. https://doi.org/10.18637/jss.v021.i11.

Smith, M. C., and R. Cutlip. 1988. Effects of infection with caprine arthritis-encephalitis virus on milk production in goats. J. Am. Vet. Med. Assoc. 193:63-67.
Snyman, M. A., and A. D. Fisher. 2019. Genetic parameters for traits associated with resistance to Haemonchus contortus in a South African Dohne Merino sheep flock. Small Rumin. Res. 176:76-88. https://doi.org/10.1016/j.smallrumres.2019.01.004.

Sorensen, D., and D. Gianola. 2002. Likelihood, Bayesian, and MCMC Methods in Quantitative Genetics. Springer Science and Business Media, New York, NY.

Stonos, N., S. K. Wootton, M. Quinton, and N. Karrow. 2013. Seroprevalence of small ruminant lentivirus infection in Ontario goat herds. Small Rumin. Res. 114:284-288. https://doi.org/10.1016/j smallrumres.2013.06.016.

Tabet, E., C. Hosri, and A. Abi-Rizk. 2015. Caprine arthritis encephalitis virus: Prevalence and risk factors in Lebanon. Rev. Sci. Tech. 34:915-921.

Tageldin, M. H., E. H. Johnson, R. M. Al-Busaidi, K. R. Al-Habsi, and S. S. Al-Habsi. 2012. Serological evidence of caprine arthritis-encephalitis virus (CAEV) infection in indigenous goats in the Sultanate of Oman. Trop. Anim. Health Prod. 44:1-3. https://doi .org/10.1007/s11250-011-9883-4.

Tariba, B., A. Kostelić, D. Šalamon, B. Roić, M. Benić, N. Prvanović Babić, and K. Salajpal. 2015. Prevalence of caprine arthritis encephalitis virus in association with clinical arthritis in six production farms of French Alpine goats in north-western Croatia. Poljoprivreda (Osijek) 21(Suppl.):135-137. https://doi.org/10.18047/ poljo.21.1.sup.31.

Thomann, B., L. C. Falzon, G. Bertoni, H. R. Vogt, G. SchüpbachRegula, and I. Magouras. 2017. A census to determine the prevalence and risk factors for caprine arthritis-encephalitis virus and visna/maedi virus in the Swiss goat population. Prev. Vet. Med. 137:52-58. https://doi.org/10.1016/j.prevetmed.2016.12.012.

Tsuruta, S., and I. Misztal. 2006. THRGIBBS1F90 for estimation of variance components with threshold and linear models. Threshold $3: 4$.

Vallerand, F., J. P. Dubeuf, and K. Tsiboukas. 2007. Le lait de brebis et de chèvre en Méditerranée et dans les Balkans: Diversité des situations locales et des perspectives sectorielles. Cah. Agric. 16:258-264. https://doi.org/10.1684/agr.2007.0111.

Vitu, C., and P. Russo. 1988. Caprine enzootic arthritis-encephalitis in France: Epidemiological and experimental studies. Comp. Immunol. Microbiol. Infect. Dis. 11:27-34. https://doi.org/10.1016/ 0147-9571(88)90005-7.

Waseem, A., R. V. S. Pawaiya, R. Singh, V. K. Gupta, K. Rajukumar, M. S. Mir, and S. Aamir. 2015. Seroprevalence of caprine arthritis encephalitis virus infection (CAEV) in Indian goats. Indian J. Vet. Pathol. 39:15-19. https://doi.org/10.5958/0973-970X.2015.00004 .8 .

White, S. N., and D. P. Knowles. 2013. Expanding possibilities for intervention against small ruminant lentiviruses through genetic marker-assisted selective breeding. Viruses 5:1466-1499. https:// doi.org/10.3390/v5061466.

Yang, W. C., H. Y. Chen, C. Y. Wang, H. Y. Pan, C. W. Wu, Y. H. Hsu, J. C. Su, and K. W. Chan. 2017. High prevalence of caprine arthritis encephalitis virus (CAEV) in Taiwan revealed by largescale serological survey. J. Vet. Med. Sci. 79:273-276. 